Org Lett. 2016 March 4; 18(5): 1096-1099. doi:10.1021/acs.orglett.6b00169.

\title{
Synthesis of 9-Substituted Triptycene Building Blocks for Solid- Phase Diversification and Nucleic Acid Junction Targeting
}

\author{
Ina Yoon $\ddagger$, Sung-Eun Suh ${ }^{\ddagger}$, Stephanie A. Barros, and Prof. David M. Chenoweth ${ }^{\star}$ \\ Department of Chemistry, University of Pennsylvania, 231 South 34th Street, Philadelphia, \\ Pennsylvania 19104, United States
}

\begin{abstract}
Triptycenes have been shown to bind nucleic acid three-way junctions but rapid and efficient methods to diversify the triptycene core are lacking. An efficient synthesis of a 9-substituted triptycene scaffold is reported that can be used as a building block for solid-phase peptide synthesis (SPPS) and rapid diversification. The triptycene building block was diversified to produce a new class of tripeptide-triptycenes and their binding abilities toward d(CAG).(CTG) repeat junctions were investigated.
\end{abstract}

\section{Graphical abstract}

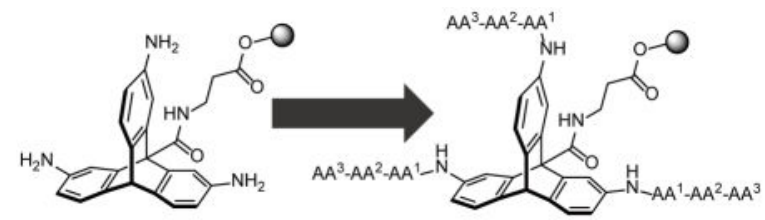

Nucleic acid junctions play important roles in many biological events. Three-way junctions (3WJs) have diverse architectures and are found in DNA and RNA, where they often serve as important structural elements. ${ }^{1}$ Several small molecules are known to bind to nucleic acid junctions. However, these molecules often lack specificity, leading to binding of various structures. ${ }^{2,3}$ Recently, we reported a new class of three-way junction stabilizers based on the triptycene scaffold. ${ }^{4}$ The unique shape and 3-fold symmetry of triptycene allows for binding to nucleic acid three-way junctions. We also reported triptycene derivatives that bind to a d(CAG).(CTG) trinucleotide repeat junction. ${ }^{5}$

Efficient strategies for triptycene diversification are needed to accelerate the discovery of new nucleic acid junction binders with enhanced specificity and binding properties.

Triptycene building blocks that are amenable to immobilization on a solid support would

"Corresponding Author: dcheno@sas.upenn.edu.

¥Author Contributions

I.Y. and S.-E.S. contributed equally.

The authors declare no competing financial interest.

Supporting Information

The Supporting Information is available free of charge on the ACS Publications website.

Experimental details and NMR spectra (PDF)

Crystallographic data for $\mathbf{5 a}(\mathrm{CIF})$ 
allow for rapid diversification and compound library construction (Scheme 1). ${ }^{6}$ To immobilize triptycene, we designed and synthesized a 9-substituted derivative that provides a point of attachment at the bridgehead, maintaining the $C_{3}$ symmetry. ${ }^{7}$ Although triptycene has been extensively modified for use in materials chemistry applications, ${ }^{8}$ functionalization at the C9-position of triptycene has rarely been reported. ${ }^{9}$

A carboxylic acid was chosen for functionalization at the $\mathrm{C} 9$ tertiary carbon of triptycene, due to its versatility of conversion into other functional groups, such as aldehyde, haloalkane, ester, and amide. The carboxylic acid group may also be removed via decarboxylation at a later stage. More importantly, the carboxylic acid group has been extensively employed for directed $\mathrm{C}-\mathrm{H}$ bond functionalization reactions, which could prove valuable during future triptycene diversification efforts. ${ }^{10,11}$

Our synthetic plan (Scheme 1) relies on reduction of the nitro groups on precursor $\mathbf{B}$ to yield building block A. Further disconnection of the amide bond at the bridgehead position affords carboxylic acid $\mathbf{C}$. A $\beta$-alanine ethyl ester was coupled to the carboxylic acid on $\mathbf{C}$. Odirected nitration was envisioned to regioselectively build three nitro groups onto triptycene D. In addition to nitration, simultaneous oxidation of the alcohol of $\mathbf{D}$ to the desired bridgehead carboxylic acid was anticipated. Next, disconnection at C9 and C10 affords benzyne and anthracene $\mathbf{E}$ precursors, which could be assembled via a Diels-Alder reaction. Precursor $\mathbf{E}$ was prepared by reduction of aldehyde $\mathbf{F}$. Early-stage functionalization of triptycene at $\mathrm{C} 9$ would provide an efficient route to a triptycene building block suitable for solid-phase immobilization and further diversification.

Commercially available anthracene-9-carbaldehyde $\mathbf{1}$ was employed as a starting material. Reduction of 1 using sodium borohydride afforded anthracen-9-ylmethanol 2 in $96 \%$ yield within one hour (Scheme 2). Prior to the addition of the Kobayashi benzyne precursor, the primary alcohol was protected with a MOM group to prevent electrophilic attack by benzyne. The Diels-Alder reaction between 3 and benzyne, which was generated in situ from 2-(trimethylsilyl)phenyltrifluoromethanesulfonate and cesium fluoride, led to the efficient formation of triptycene $\mathbf{4}$ in high yield.

Treatment of $\mathbf{4}$ with nitric acid resulted in nitration of the aromatic rings. During the nitration reaction the protecting group on the alcohol was simultaneously deprotected and oxidized to the carboxylic acid, providing $\mathbf{6 a}$ along with two other isomers $\mathbf{6 b}$ and $\mathbf{6 c}$. The nitrated triptycene isomers proved inseparable by silica gel chromatography. Acid-catalyzed esterification of the crude mixture provided ester isomers $\mathbf{5 a}-\mathbf{5} \mathbf{c}$, which were separated via silica gel chromatography. The structures of ester isomers $\mathbf{5 a}-\mathbf{5 c}$ were confirmed by twodimensional NMR spectroscopy, HMBC and HSQC. Single crystals of 5a were grown in $\mathrm{CHCl}_{3} / \mathrm{CH}_{2} \mathrm{Cl}_{2} / \mathrm{CH}_{3} \mathrm{OH}$, and the structure was determined by X-ray crystallography (Scheme 2). Following separation of each isomer, saponification was performed to convert the ester to a carboxylic acid for coupling to an amine linker. Nitration on the alpha-carbon was not observed due to its higher electronegativity compared to that of beta-carbons. ${ }^{11}$

To investigate the O-directing effect observed during nitration and to further reduce the number of undesired side products, compound $\mathbf{8}$, containing a carboxylic acid at the $\mathrm{C} 9$ 
position, was prepared by deprotection of $\mathbf{4}$ followed by $\mathrm{KMnO}_{4}$ oxidation (Scheme 3). Compounds 4, 7, and 8 were treated with excess nitric acid at $80^{\circ} \mathrm{C}$ for $24 \mathrm{~h}$, and the crude mixtures were analyzed by HPLC using 9,10-diphenylanthrancene as an internal standard. HPLC analysis demonstrated that nitration of $\mathbf{8}$ led to fewer side products compared to nitration of $\mathbf{4}$ and $\mathbf{7}$ (Supporting Information).

Interestingly, nitration of 7 produced little of desired products $\mathbf{6 a - 6 c}$. The composition of $\mathbf{6 a}$ and $\mathbf{6 c}$ significantly changed compared to that from the nitration of $\mathbf{4}$ and $\mathbf{8}$, and the overall yield increased for the nitration of $\mathbf{8}$. Attempts were made to increase the proportion of $\mathbf{6 a}$ over that of the other isomers. The highest ratio of $\mathbf{6 a}$ to $\mathbf{6} \mathbf{b}$ achieved using this nitration method was $0.33 .{ }^{12}$ The introduction of a carboxylic acid at the $\mathrm{C} 9$ position of triptycene significantly increased the ratio of $\mathbf{6 a}$ to $\mathbf{6} \mathbf{b}$ to 0.81 . These observations are consistent with the carboxylic acid functioning as a directing group during the nitration reaction.

Isomer 6a was chosen for further elaboration due to its three-fold symmetry, which is complementary to that of nucleic acid 3WJs. To extend the length of the linker at the 9position, several standard reaction conditions for amide bond formation were examined. However, the amidation reaction proved recalcitrant and all attempted conditions resulted in unreacted starting material (Table 1, entries 2-4). The coupling of 9-triptycenecarboxylic acid derivatives with EDC has been previously reported. ${ }^{13}$ However, this method was not reproducible using $\mathbf{6 a}$ as the starting material (Table 1, entry 1). Our results suggested that the sterically hindered environment around the carboxylic acid prevents coupling of amines under standard conditions, possible due in part to the bulky active ester intermediates. After a comprehensive literature search, we were inspired by Nicolaou's use of methanesulfonyl chloride $(\mathrm{MsCl})$ in the total synthesis of the $\mathrm{CP}$ molecules to overcome limitations of a difficult Arndt-Eistert homologation on sterically encumbered carboxylic acids. ${ }^{14}$ Triethylamine and $\mathrm{MsCl}$ were added to $\mathbf{6 a}$ followed by addition of $\beta$-alanine ethyl ester hydrochloride, which was pre-treated with triethylamine at $0{ }^{\circ} \mathrm{C}$. After warming to room temperature, 9 was synthesized in $48 \%$ yield (Table 1, entry 7 ). However, complete conversion of the starting material was not achieved under these conditions. To drive the reaction to completion, the base was changed to pyridine, which is less sterically hindered and allows for access to the carboxylic acid near the bridge-head position. The solvent was also changed to dichloromethane due to solubility issues. These changes led to completion of the reaction within one hour after warming to room temperature and a substantial increase in the yield to $92 \%$ (Table 1, entry 5). A decrease in the equivalence of $\mathrm{MsCl}$ and pyridine decreased the yield to $61 \%$ (Table 1, entry 6). Among the various amide bond forming reaction conditions tested on triptycene $\mathbf{6 a}$, only the mesylation route afforded the desired product in high yield.

$\mathrm{Pd} / \mathrm{C}$-catalyzed hydrogenation of $\mathbf{9}$ led to reduction of the three nitro groups to afford triaminotriptycene 10. Next, the free amines were protected with Fmoc groups by treatment with Fmoc-chloride and pyridine. The linker ester group was hydrolyzed in the presence of sulfuric acid and water to produce acid $\mathbf{1 2}$. The free carboxylate of fully protected building block 12 allowed for attachment to 2-chlorotriyl chloride resin, which is compatible with Fmoc deprotection chemistry (Scheme 4). After attachment to resin, the Fmoc groups were deprotected using $20 \%$ piperidine in dimethylformamide to generate the free amines. The 
corresponding Fmoc-protected amino acid was pre-activated with HATU and N,Ndiisopropylethylamine (DIPEA) and added to the deprotected triptycene on resin. (L)histidine, (L)-lysine, and (L)-asparagine were selected for attachment to the triptycene arms. The deprotection and coupling steps were repeated until the desired sequence of amino acids was achieved (Scheme 5a). Once the desired peptide was synthesized on solid phase, the triptycene derivatives were cleaved from the resin with simultaneous deprotection of the amino acid side chain protecting groups by treatment with a cleavage solution $(9: 1: 1$ trifluoroacetic acid (TFA) : 2,2,2-trifluoroethanol (TFE) : dichloromethane). Asparagine, which was coupled at the N-terminus, required longer cleavage times due to the slow deprotection rate of the trityl group close to the amino group (Scheme 5b). ${ }^{15}$ Each compound was purified by preparative reverse-phase HPLC and analyzed by analytical HPLC and MALDI-MS.

Triptycenes 17-19 were evaluated for binding towards a d(CAG) $(\mathrm{CTG})$ trinucleotide repeat junction using a previously developed fluorescence-quenching experiment. ${ }^{5}$ The binding of triptycenes 17-19 were compared to a previously reported triptycene that binds to the junction. The previously reported junction binder $(\mathbf{2 0})$ is analogous to $\mathbf{1 7}$ but lacks the linker at the 9-position. $\mathrm{A} d(\mathrm{CAG}) \cdot(\mathrm{CTG})$ repeat junction was labelled with a fluorophore (FAM) and a quencher (IowaBlk). This labelled $3 \mathrm{WJ}$ was pre-incubated with a 10 bp inhibitor (I10) strand that is complementary to the junction. Hybridization of the inhibitor strand to the junction results in an open form, leading to an increase in fluorescence (Figure 1a). Triptycenes 17-20 were added to the pre-incubated fluorescent form. Binding of the triptycenes leads to displacement of $\mathrm{I} 10$ and reformation of the $3 \mathrm{WJ}$, resulting in a decrease in fluorescence. The $\mathrm{K}_{\mathrm{d}}$ value for triptycene 17 was determined to be $8.38 \mu \mathrm{M}$ and exhibited a slight decrease in binding compared to that of triptycene 20 (i.e., $\mathrm{K}_{\mathrm{d}}$ value of $1.76 \mu \mathrm{M}$ ). Triptycenes 18 and 19, containing di- or tripeptides substituents, exhibited enhanced binding affinity toward the junction compared to that of 20 with $\mathrm{K}_{\mathrm{d}}$ values of $0.27 \mu \mathrm{M}$ and $0.46 \mu \mathrm{M}$, respectively (Figure 1b). The presence of lysine appears to play an important role in binding to the junction and will be investigated in future studies.

In summary, we have developed a synthetic approach for preparing new 9-substituted triptycene building blocks. This approach enables solid-phase diversification of triptycene. During the synthesis, O-directed nitration was observed from the MOM protected primary alcohol (4), primary alcohol (7), and carboxylic acid (8) at the C9 position of triptycene. These results indicated that the carboxylic group increased the ratio of nitration on betacarbons toward the linker position, pointing to a possible carboxylic acid directing effect. In addition, a key amide bond formation was achieved on a sterically hindered and geometrically fixed tertiary carboxylic acid using a unique $\mathrm{MsCl}$ activation strategy. This may be regarded as a general strategy toward functionalization of extremely sterically encumbered tertiary carboxylic acids. For diversification of the new triptycene building block, three amino acids were utilized including histidine, lysine, and asparagine to produce tris-peptide. The binding ability of the synthesized triptycene derivatives toward a d(CAG). (CTG) trinucleotide repeat junction was evaluated and triptycene 18 and 19 exhibited better binding affinity to the junction compared to that of a previously reported triptycene with no linker (20). This new synthetic strategy provides rapid and efficient access to triptycene 
building blocks, enabling high-throughput diversification for rapid evaluation of potential junction binders and other medicinal chemistry targets.

\section{Supplementary Material}

Refer to Web version on PubMed Central for supplementary material.

\section{Acknowledgments}

This work was supported by funding from the University of Pennsylvania. We thank Pat Carroll (University of Pennsylvania) for X-ray crystallographic assistance. The instruments were supported by the National Science Foundation and the National Institutes of Health including HRMS (Grant NIH RR-023444) and X-ray diffractometer (Grant CHE-0840438). I.Y. is grateful for support from a fellowship from the Kwanjeong Educational Foundation.

\section{References}

1. (a) Duckett DR, Lilley DMJ. EMBO J. 1990; 9:1659-1664. [PubMed: 2328731] (b) Shlyakhtenko LS, Potaman VN, Sinden RR, Gall AA, Lyubchenko YL. Nucleic Acids Res. 2000; 28:3472-3477. [PubMed: 10982865] (c) Lilley DMJ. Q Rev Biophisics. 2000; 33:109-159.

2. (a) Tor Y. ChemBioChem. 2003; 4:998-1007. [PubMed: 14523917] (b) Thomas JR, Hergenrother PJ. Chem Rev. 2008; 108:1171-1224. [PubMed: 18361529] (c) Blond A, Ennifar E, Tisné C, Micouin L. ChemMedChem. 2014; 9:1982-1996. [PubMed: 25100137]

3. Guan L, Disney MD. ACS Chem Biol. 2012; 7:73-86. [PubMed: 22185671]

4. Barros SA, Chenoweth DM. Angew Chem Int Ed. 2014; 53:13746-13750.

5. Barros SA, Chenoweth DM. Chem Sci. 2015; 6:4752-4755. [PubMed: 26366282]

6. (a) Boas U, Brask J, Jensen KJ. Chem Rev. 2009; 109:2092-2118. [PubMed: 19290595] (b) Guillier F, Orain D, Bradley M. Chem Rev. 2000; 100:2091-2158. [PubMed: 11749285]

7. (a) Bartlett PD, Cohen SG, Cotman JD, Kornblum N, Landry JR, Lewis ES. J Am Chem Soc. 1950; 72:1003-1004.(b) Bartlett PD, Lewis ES. J Am Chem Soc. 1950; 72:1005-1009.

8. (a) Swager TM. Acc Chem Res. 2008; 41:1181-1189. [PubMed: 18759462] (b) Chong JH, MacLachlan MJ. Chem Soc Rev. 2009; 38:3301-3315. [PubMed: 20449050]

9. Ng KKD, Hart H. Tetrahedron. 1995; 51:7883-7906.

10. (a) Wang D, Mei T, Yu J. J Am Chem Soc. 2008; 130:17676-17677. [PubMed: 19067651] (b) Zhang Y, Zhao H, Zhang M, Su W. Angew Chem Int Ed. 2015; 54:3817-3821.(c) Wang DH, Engle KM, Shi BF, Yu JQ. Science. 2010; 327:315-320. [PubMed: 19965380]

11. Harsanyi MC, Norris RK, Sze G, Witting PK. Aust J Chem. 1995; 48:1949-1967.

12. (a) Klanderman BH, Perkins WC. J Org Chem. 1969; 34:630-633.(b) Chong JH, MacLachlan MJ. J Org Chem. 2007; 72:8683-8690. [PubMed: 17929866] (c) Chong JH, MacLachlan MJ. Inorg Chem. 2006; 45:1442-1444. [PubMed: 16471955] (d) Zhang C, Chen CF. J Org Chem. 2006; 71:6626-6629. [PubMed: 16901157] (e) Ma YX, Meng Z, Chen CF. Synlett. 2015; 26:6-30.

13. Xu ML, Huang W. Synth Commun. 2014; 44:3435-3440.

14. Nicolaou KC, Baran PS, Zhong YL, Choi HS, Yoon WH, He Y, Fong KC. Angew Chem Int Ed. 1999; 38:1669-1675.

15. (a) Friede M, Denery S, Neimark J, Kieffer S, Gausepohl H, Briand JP. Pept Res. 1992; 5:145-147. [PubMed: 1421802] (b) Quesnel A, Briand JP. J Pept Res. 1998; 52:107-111. [PubMed: 9727866] 
a)

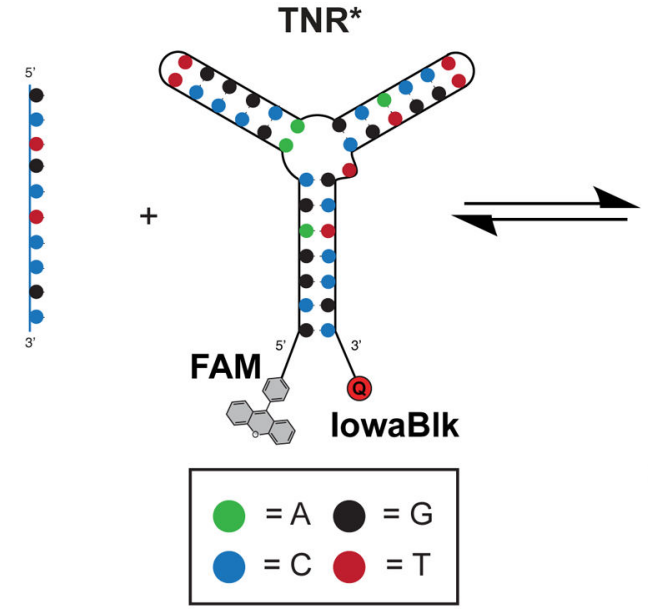

b)

\begin{tabular}{cc}
\hline compound & $\mathrm{K}_{\mathrm{d}}(\mu \mathrm{M})$ \\
\hline 17, Trip-(His) $)_{3}$ & $8.38 \pm 1.358$ \\
18, Trip-(His-Lys) $)_{3}$ & $0.269 \pm 0.055$ \\
19, Trip-(His-Lys-Asn) $)_{3}$ & $0.460 \pm 0.092$ \\
20, Trip-(His) ${ }_{3}{ }^{*}$ & $1.76 \pm 0.215$ \\
\hline
\end{tabular}

$\mathrm{TNR}^{*}-\mathrm{I10}$

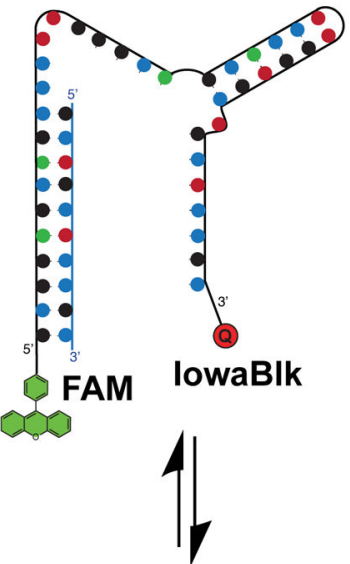

TNR*-Trip

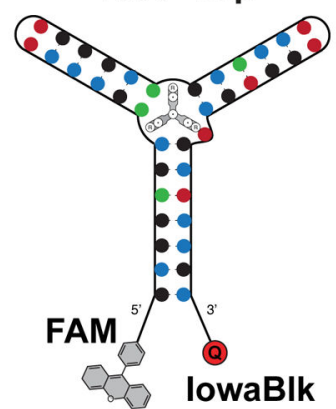

Figure 1.

(a) Graphical representation of the fluorescence-quenching 3WJ assay. (b) Dissociation constants of triptycenes 17-20. Note: Synthesis of triptycene 20 lacking a bridgehead substituent has been previously reported. ${ }^{5}$ 


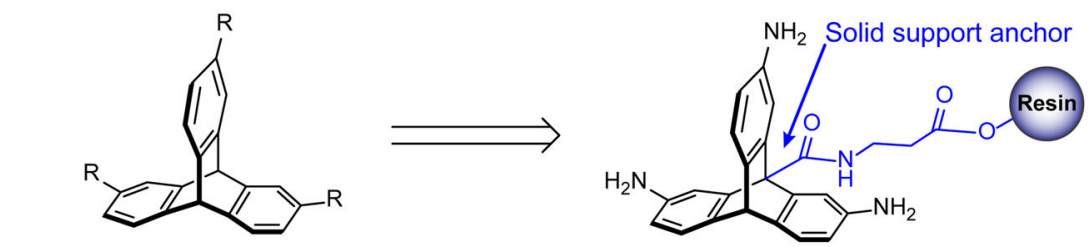

- Known nucleic acid 3WJ binders

- Low-throughput diversification

- Key building block for immobilization

- High-throughput diversification

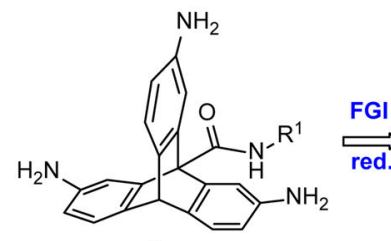

A<smiles>O=[R]CCCC(=O)O</smiles>

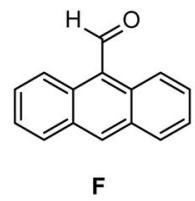

(in this work)

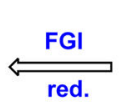

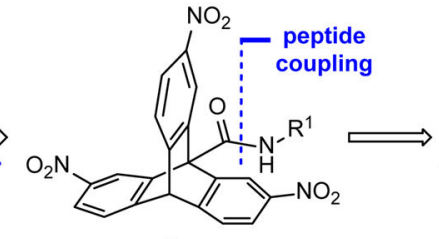

B

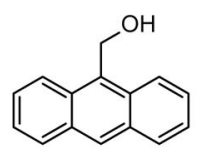

E
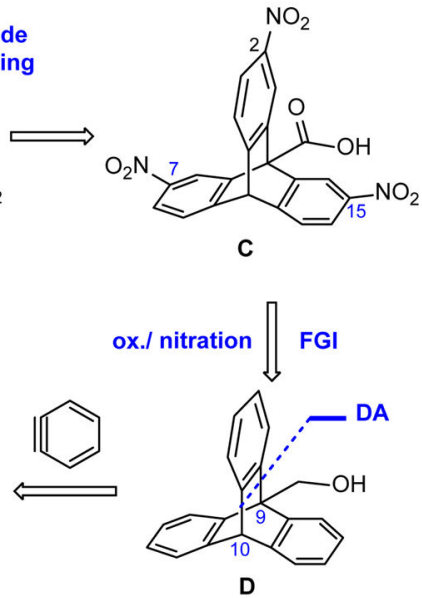

Scheme 1.

Strategy for Triptycene Solid-Phase Diversification and Retrosynthesis of Key Building Block A. SPPS = Solid-Phase Peptide Synthesis; FGI = Functional Group Interconversion; ox. $=$ oxidation $;$ red. $=$ reduction $; \mathrm{DA}=$ Diels-Alder reaction 
<smiles>O=Cc1c2ccccc2cc2ccccc12</smiles>

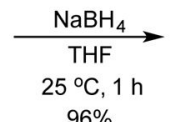

$96 \%$

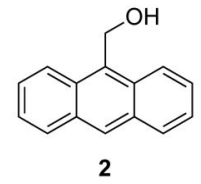

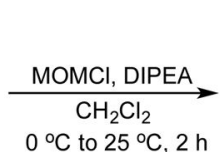

$0{ }^{\circ} \mathrm{C}$ to $25^{\circ} \mathrm{C}, 2 \mathrm{~h}$

$91 \%$

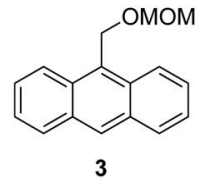

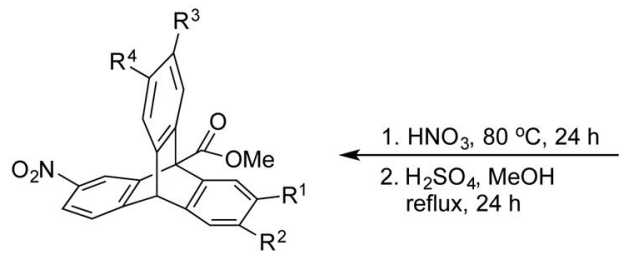

5a, $\mathrm{R}^{1}, \mathrm{R}^{3}=\mathrm{NO}_{2} ; \mathrm{R}^{2}, \mathrm{R}^{4}=\mathrm{H}$

5b, $R^{1}, R^{4}=\mathrm{NO}_{2} ; R^{2}, R^{3}=\mathrm{H}$

5c, $R^{2}, R^{4}=\mathrm{NO}_{2} ; R^{1}, R^{3}=H$

$1 \mathrm{M} \mathrm{NaOH}(\mathrm{aq}) \mid \begin{gathered}p \text {-dioxane } \\ 60^{\circ} \mathrm{C}, 24 \mathrm{~h}\end{gathered}$

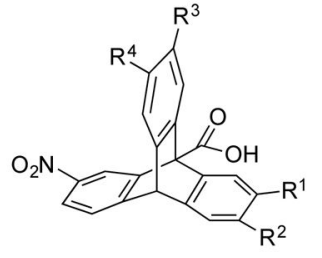

6a, $\mathrm{R}^{1}, \mathrm{R}^{3}=\mathrm{NO}_{2} ; \mathrm{R}^{2}, \mathrm{R}^{4}=\mathrm{H}$

$6 b, R^{1}, R^{4}=N_{2}^{2} ; R^{2}, R^{3}=H$

6c, $\mathrm{R}^{2}, \mathrm{R}^{4}=\mathrm{NO}_{2} ; \mathrm{R}^{1}, \mathrm{R}^{3}=\mathrm{H}$
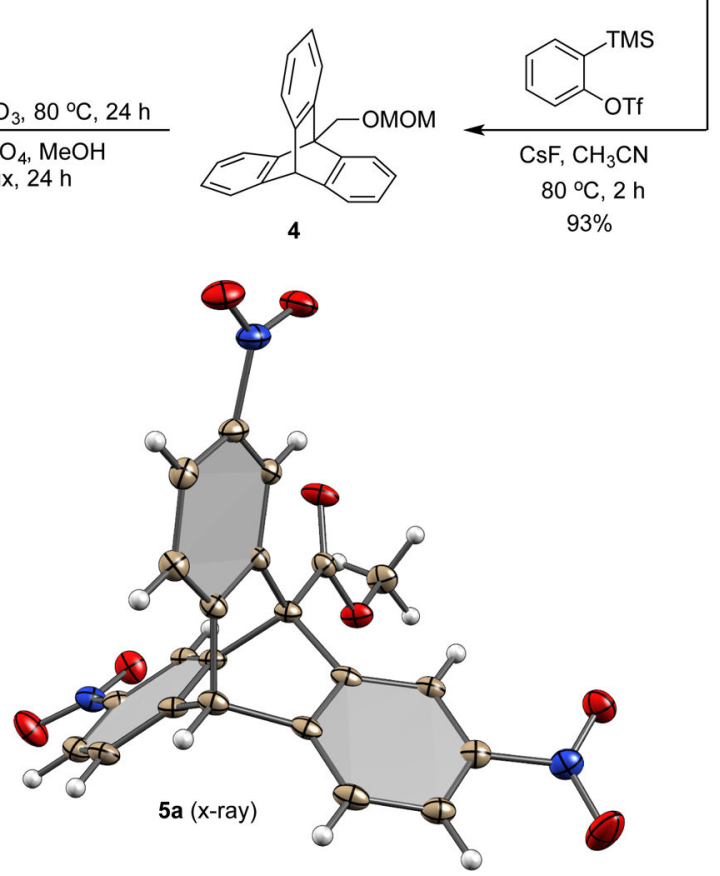

Scheme 2.

Approach Toward the Synthesis of 9-substituted Trifunctionalized Triptycene 6a-6c and Xray Crystal Structure of $5 \mathrm{a}$ 

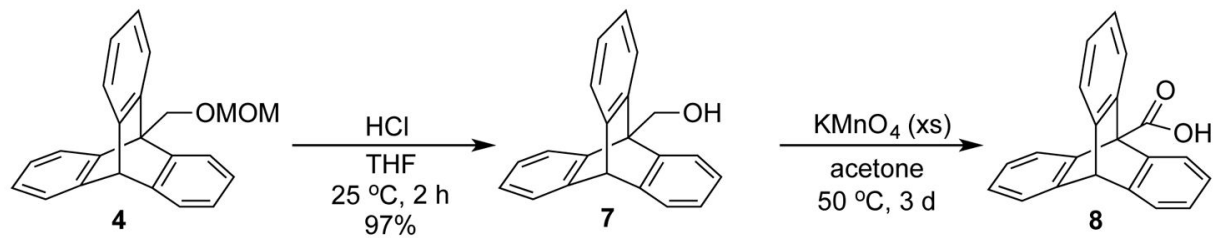

$\mathrm{HNO}_{3}$

$80^{\circ} \mathrm{C}, 24 \mathrm{~h}$

$\mathrm{HNO}_{3}$

$\mathrm{HNO}_{3}$ $80^{\circ} \mathrm{C}, 24 \mathrm{~h}$ $80^{\circ} \mathrm{C}, 24 \mathrm{~h}$
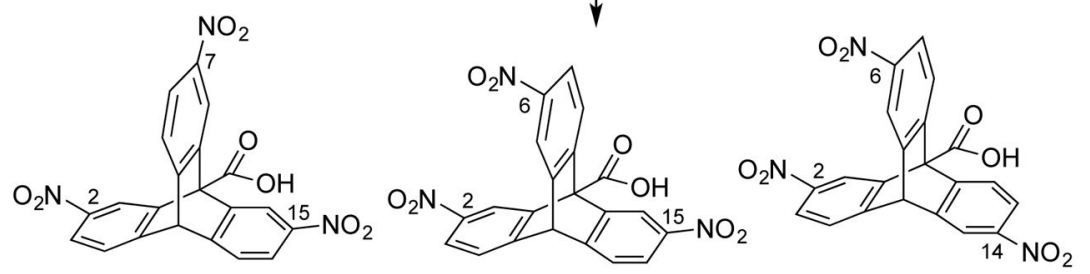

\begin{tabular}{|l|c|c|c|c|}
\hline & $\mathbf{6 a}$ & $\mathbf{6 b}$ & $\mathbf{6 c}$ & overall \\
\hline $\mathbf{4}$ & $16 \%$ & $34 \%$ & $22 \%$ & $72 \%$ \\
$\mathbf{7}$ & $0.8 \%$ & $0.7 \%$ & $0.9 \%$ & $2.4 \%$ \\
$\mathbf{8}$ & $30 \%$ & $37 \%$ & $13 \%$ & $80 \%$ \\
\hline
\end{tabular}

Scheme 3.

Compositions of $6 a-6 c$ from the Nitration of Compounds 4,7 , and 8 

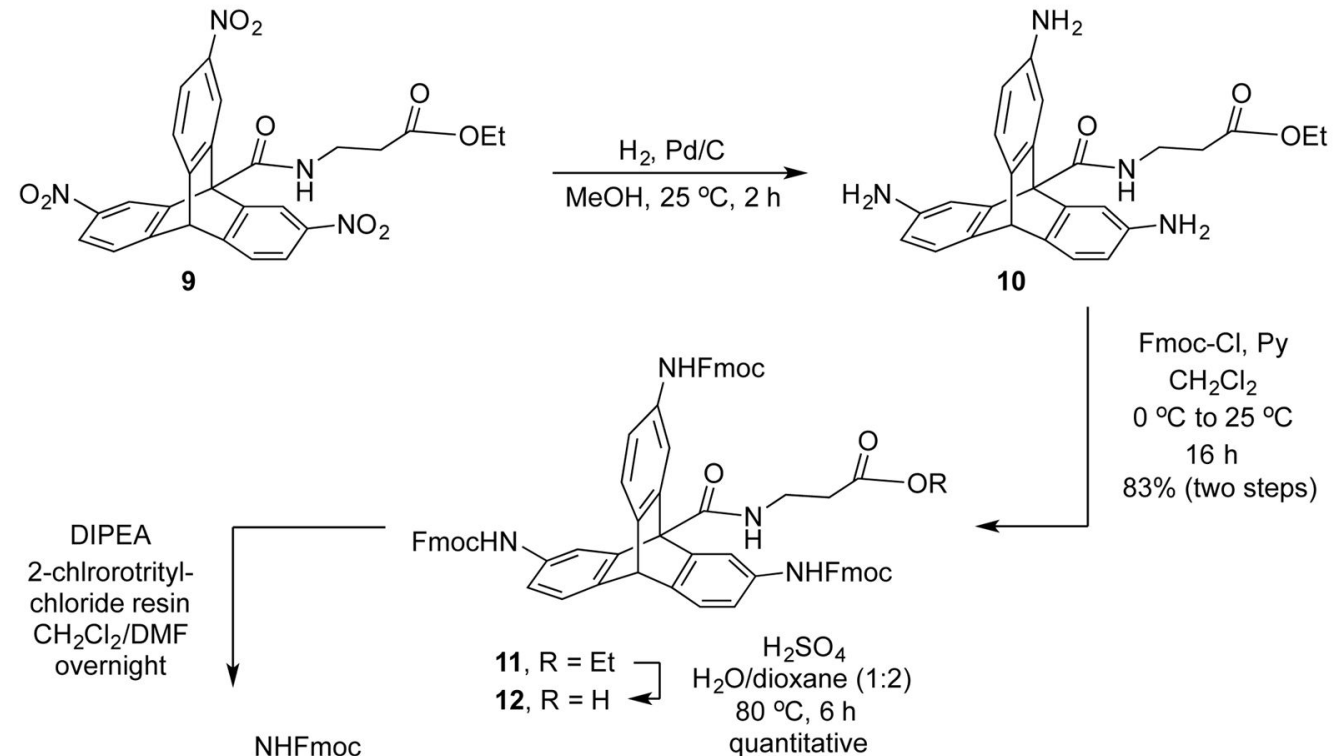

NHFmoc

12, $\mathrm{R}=\mathrm{Et} \quad \mathrm{H}_{2} \mathrm{O} /$ dioxane (1:2)

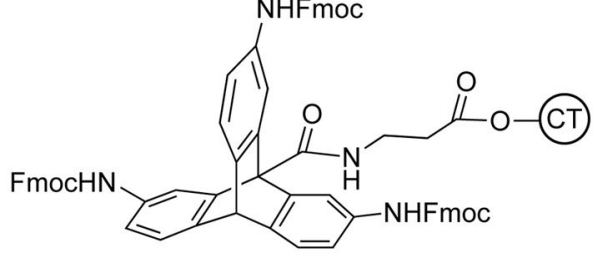

quantitative

13

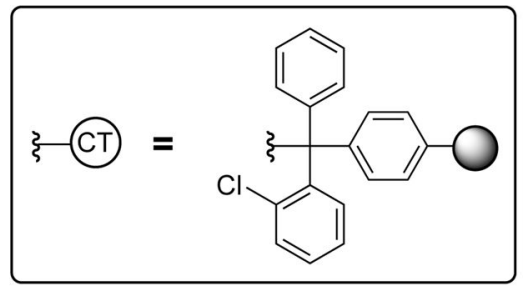

Scheme 4.

Synthesis of SPPS Precursor 12 and Loading on 2-Chlorotrityl Chloride Resin 


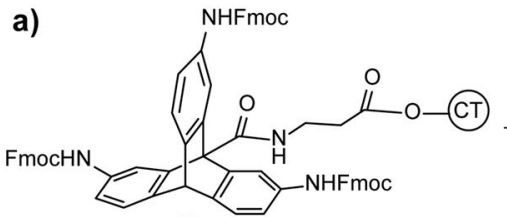

13
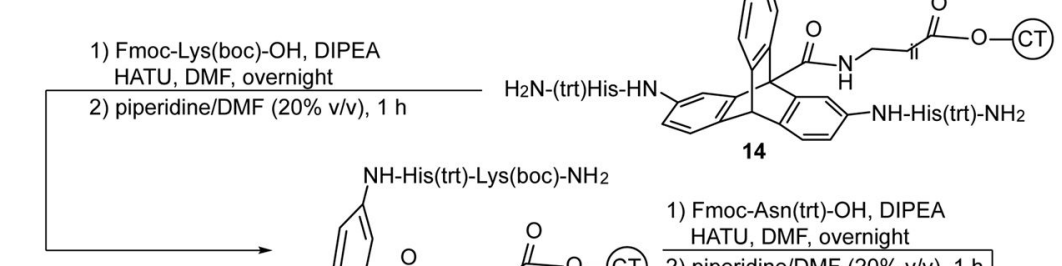
$\mathrm{NH}-\mathrm{His}(\mathrm{trt})-\mathrm{Lys}(\mathrm{boc})-\mathrm{NH}_{2}$
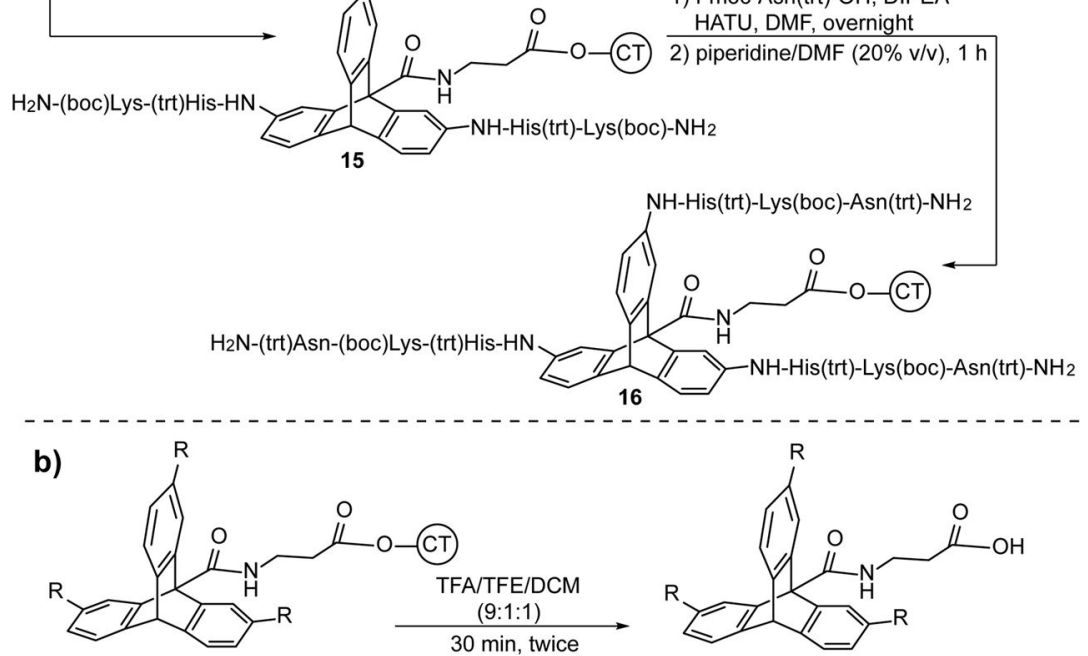

14, $\mathrm{R}=\mathrm{NH}-\mathrm{His}(\mathrm{trt})-\mathrm{NH}_{2}$

15, $\mathrm{R}=\mathrm{NH}-\mathrm{His}(\mathrm{trt})-\mathrm{Lys}(\mathrm{boc})-\mathrm{NH}_{2}$

16, $\mathrm{R}=\mathrm{NH}-\mathrm{His}(\mathrm{trt})-\mathrm{Lys}\left(\right.$ boc) - Asn(trt)- $\mathrm{NH}_{2}$

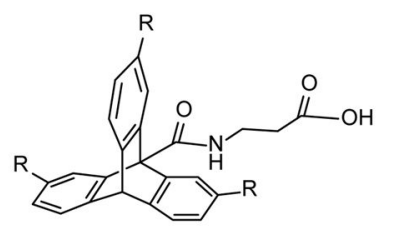

18, $\mathrm{R}=\mathrm{NH}$-His-Lys- $\mathrm{NH}_{2}$

19, $\mathrm{R}=\mathrm{NH}$-His-Lys-Asn- $\mathrm{NH}_{2}^{*}$
17, $\mathrm{R}=\mathrm{NH}-\mathrm{His}-\mathrm{NH}_{2}$

Scheme 5. (a) Solid-Phase Peptide Synthesis of 9-substituted Triptycene on 2-Chlorotrityl Chloride Resin (b) Cleavage from the Resin to Generate Triptycene Derivatives 17-19

*Deprotection required $12 \mathrm{~h}$ for triptycene 19. CT $=2$-chlorotrityl chloride resin. 


\section{Table 1}

\section{Reaction Conditions for Amide Bond Formation at the Linker Position}

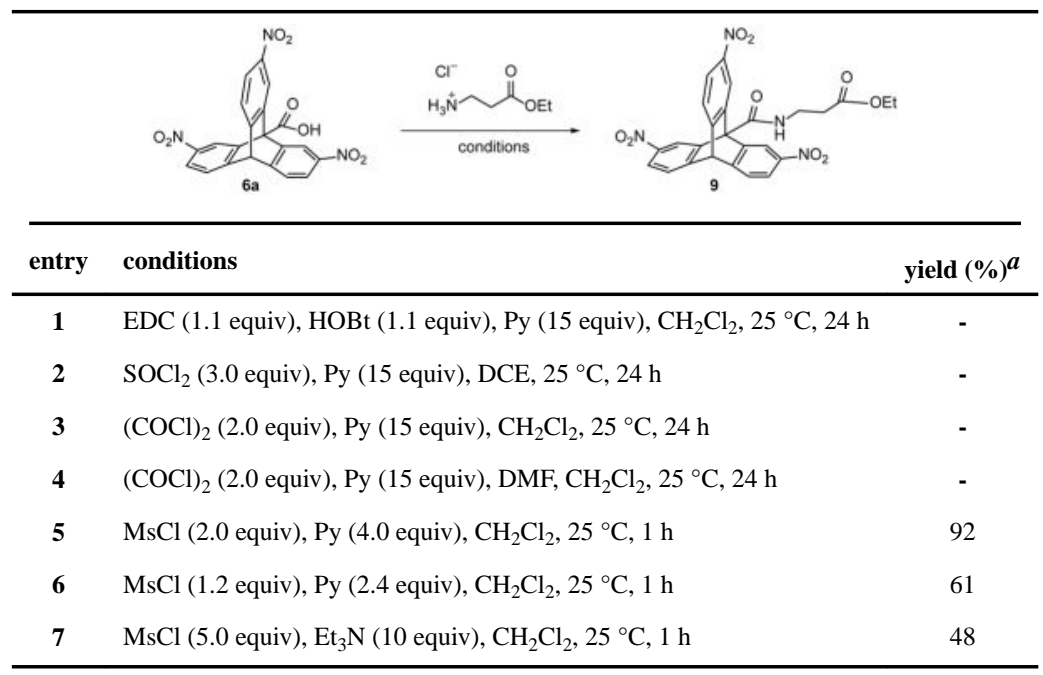

${ }^{a}$ NMR yield. Durene was used as an internal standard. 